\title{
Consumers' response to different shelf life food labelling
}

\author{
D. Dordevic ${ }^{1,2}$, R. M. Cazalilla ${ }^{3}$, Z. Javurkova ${ }^{1}$, H. Buchtova ${ }^{4}$ and S. Jancikova $^{1}$ \\ ${ }^{1}$ Department of Plan Origin Foodstuffs Hygiene and Technology, Faculty of Veterinary Hygiene and Ecology, University of \\ Veterinary and Pharmaceutical Sciences, Brno, Czech Republic; ${ }^{2}$ Department of Technology and Organization of Public \\ Catering, South Ural State University, Chelyabinsk, Russia; ${ }^{3}$ Faculty of Health and Sciences, University of Jaen, Jaen, \\ Spain; ${ }^{4}$ Department of Meat Hygiene and Technology, Faculty of Veterinary Hygiene and Ecology, University of Veterinary \\ and Pharmaceutical Sciences, Brno, Czech Republic
}

Corresponding Author: Dani Dordevic, dani_dordevic@yahoo.com

Received: 15 November 2019 / Accepted: 9 June 2020 / Published: 6 July 2020

(c) 2020 Codon Publications

OPEN ACCESS (C) (i) (); ()

RESEARCH ARTICLE

\begin{abstract}
Respondents' perception about the possible changes of best before date (BBD) to the date of the highest quality was the main aim of the survey. The survey consisted out of 1,107 respondents who were grouped according to their demographic characteristics and food labelling preferences. The results of the survey are indicating high acceptance rate towards new labelling, but without clear connection with their preferences. Another aspect of the research emphasised the respondents' perception towards the price of healthier food commodities and revealed that education level has high impact $(P<0.05)$ on their opinion and considerations. The survey gave important answers on possibility of changes of food labelling by which it would be affected food waste quantities. Certainly, each food type shelf life should be checked and labelled according to food perishability and consumers safeness. The changing of the BBD to the date of the highest quality according to our survey would be broadly accepted among all socio-demographic groups.
\end{abstract}

Keywords: food labelling, food waste, best before date (BBD), use-by dates (UBD), healthy food

\section{Introduction}

Food labelling represents one of the main instruments of the food strategy and plays an important role between production, retailing and consumption. Following issues are connected with food labelling: roles and responsibilities of government, contemporary definition and distribution of the food industry. Similar to all other rules and legislation, labelling is constantly changing in the way that it can respond in an improved way to contemporary challenges in the food market. Food labelling is also connected with bad or good management with the unnecessary disposal of edible food. There has been a constant pursuit to make food labelling not confusing and also to make clear the indication when food is safe for the consumption (Milne, 2012). Caroline Spelman in 2011 introduced new expiry dates guidelines to emphasise the food labelling confusion with 'use-by date (UBD)' and 'best before date (BBD)' and to prevent the food waste (Milne, 2012).

Food preferences are implicated with different factors as age, gender, culture and socio-economic status (SES) (Caine-Bish and Scheule, 2009). SES includes indicators out of which three most common are education, social class and income (Darin-Mattsson et al., 2017). Usually consumers' higher socioeconomic status results in better food nutrition knowledge which then leads to more beneficial diet choice (Beydoun and Wang, 2008).

Food labelling provides information about the food products to consumers such as a list of ingredients, quantity, nutritional value, origin, treatment, allergens, packaging, storage conditions and shelf life (Van Boxstael et al., 2014). Summarising, BBD is connected mainly to food quality (e.g. taste, appearance, texture), while UBD is 
connected with food safety (Food Standards Agency [FSA], 2018; Milne, 2012). Microbiologically high perishable food could be dangerous for human health and that is the reason for switching BBD to UBD. After expiration of UBD, the consumption is not safe (Regulation (EU) No. 1169/2011; Article 24). Surveys are indicating that the most important information for consumers on food labelling is the date of food expiration, even more important than food price (Nakov et al., 2017). On the contrary, the literature data are indicating that these types of food labelling concerning food shelf life are often confusing and probably leading to increased level of food waste (Anthesis et al., 2018; Wilson et al., 2017). Other information from food labelling are also important for consumers, such as information about nutrition that is in relation with consumer age and education level (Grunert et al., 2010; Hassan and Dimassi, 2017). It has been found that non-negligible (15.7\%) number of consumers do not read food labelling due to reasons such as time consuming and comprehension (Hassan and Dimassi, 2017).

The study had the aim to evaluate respondents' considerations towards possible changing of shelf life food labelling and to investigate factors influencing the price of healthier food, same as issues concerning food waste.

\section{Material and methods}

The questionnaires were carried out both in-person and online. They were filled out in Czech language with the use of Google forms/docs. The research group consisted of 1,107 respondents. The study was conducted between February 2018 and June 2018. The questionnaire counted
40 questions, consisting of two parts. The first part $(n=8)$ was about socio-demographic characteristics of respondents (Table 1); the second part considered questions about respondents' health conditions $(n=5)$; and the third part was about questions that gathered information about respondents' food labelling preferences $(n=27)$. More females $(78.3 \% ; n=867)$ than males $(19.8 \% ; n=219)$ participated in the survey, and most of them were not married $(79.8 \% ; n=883)$.

\section{Statistical analysis}

SPSS 20 IBM (IBM Corporation, Armonk, USA) statistical computer software was used for all statistical analyses. The comparison of data was based on $t$-test and one-way ANOVA analysis with post hoc Turkey's test for finding differences within more than two variances. Additional information about the association of variables was provided by chi-squared tests.

\section{Results and discussion}

\section{Frequency of shopping}

The frequency of shopping is shown in Figures 1 (depending on age) and 2 (depending on current status). Chi-square test showed that frequency of shopping is significantly $(P<0.05)$ reduced among respondents' belonging to age groups (45-60 years and over 60 years), though the frequency of shopping is significantly higher among people in the age group of 35-45 years. On the contrary, the frequency of shopping is significantly $(P<0.05)$ reduced among retired respondents than the

Table 1. Demographic information about respondents $(100 \% ; n=1107)$.

\begin{tabular}{|c|c|c|c|c|}
\hline Demographic category & Groups & $\begin{array}{l}\text { Number }(n) \text { of } \\
\text { respondents }\end{array}$ & $\begin{array}{l}\text { Percentage }(\%) \\
\text { of respondents }\end{array}$ & $\begin{array}{c}\text { Unanswered questions } \\
\qquad n / \%\end{array}$ \\
\hline \multirow[t]{2}{*}{ Gender } & Female & 867 & 78.3 & $21 / 1.9$ \\
\hline & Male & 219 & 19.8 & \\
\hline \multirow[t]{2}{*}{ Marital status } & Married & 206 & 18.6 & $18 / 1.6$ \\
\hline & Not married & 883 & 79.8 & \\
\hline \multirow[t]{3}{*}{ Educational level } & Elementary school & 98 & 8.9 & $298 / 26.9$ \\
\hline & Secondary school & 697 & 63.0 & \\
\hline & Higher education & 14 & 1.3 & \\
\hline \multirow[t]{5}{*}{ Current status } & Student & 21 & 1.9 & $13 / 1.2$ \\
\hline & An employee of state & 57 & 5.1 & \\
\hline & SEP (self-employed people) & 665 & 60.1 & \\
\hline & Unemployed & 49 & 4.4 & \\
\hline & Retired & 302 & 27.3 & \\
\hline \multirow[t]{3}{*}{ Income group* } & Below average (<550 EUR) & 667 & 60.3 & $129 / 11.6$ \\
\hline & Average (550-1100 EUR) & 239 & 21.6 & \\
\hline & Above average (>1100 EUR) & 72 & 6.5 & \\
\hline
\end{tabular}




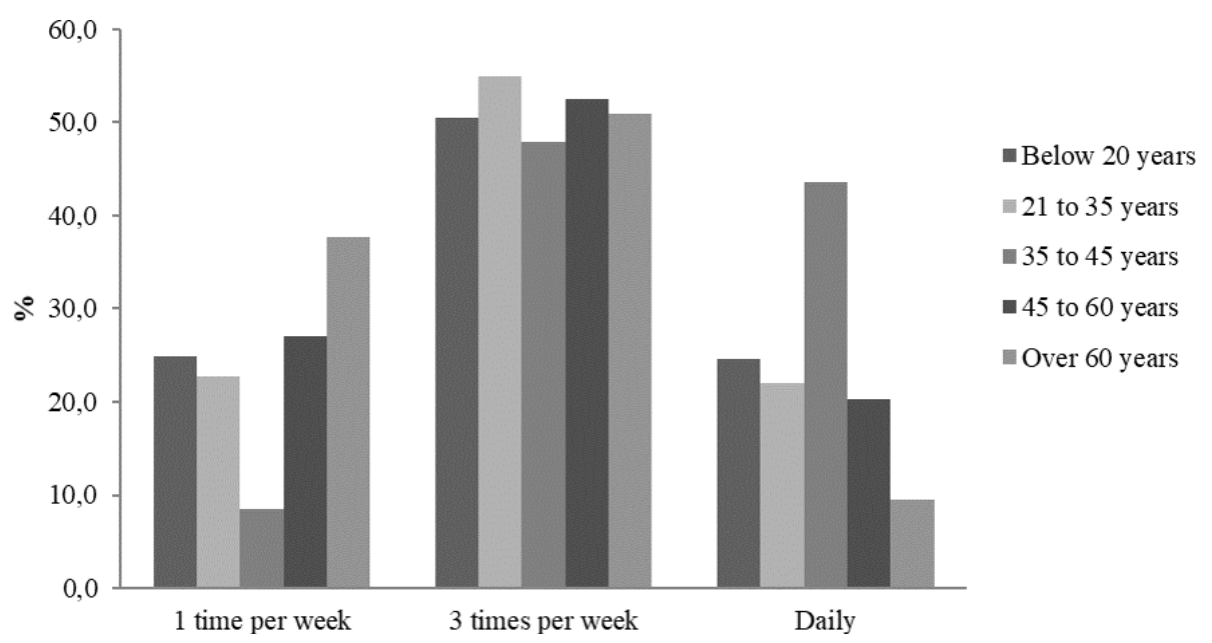

Figure 1. Frequency of shopping according to respondents' age.

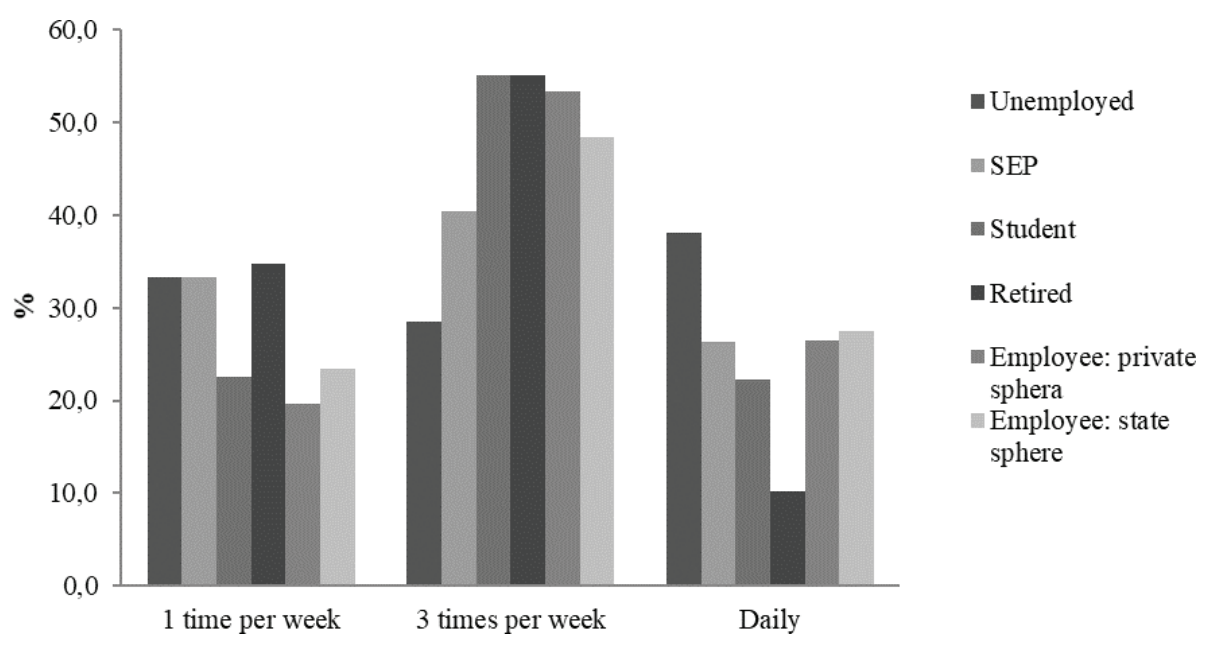

Figure 2. Frequency of shopping according to respondents' current status.

rest (though respondents from this group do shopping usually three times per week) (Figure 2). There was no statistical $(P>0.05)$ influence of other investigated sociodemographic parameters on shopping frequency.

Approximately half (about 50\%) of respondents (regardless of age group) stated that they do food purchase 3 times per week. According to gained results, noticeable differences can be observed between respondents' age group younger than 35 years and over 35 years.

The frequency of food purchase among respondents under 35 years was similar, with approximately the same percentage of respondents in both age groups (below 20 years, $21-35$ years) buying both 1 time per week and daily. A slightly different trend of responses compared with respondents under the age of 35 was found in the 45-60 years group. The opposite trend was found in the remaining two groups of respondents (35-45 years and over 60 years). Regarding 35-45 age group, the frequency of daily purchase was slightly lower than three times per week purchase, while less than $10 \%$ of respondents purchase 1 time per week. Respondents in the age group over 60 years stated that $10 \%$ of them do food purchase daily, while $40 \%$ do it 1 time per week.

Consumers' shopping frequencies can also be highly affected by specific food commodity promotions that are at the present time very often the part of shopping culture in many parts of the world, especially in developed regions, such as the European Union (Namin and Dehdashti, 2019). Other factors affecting shopping frequency are number of family members, current status, age and gender. The frequency of shopping was reduced in the upper age group, especially among retired respondents. This result is supported by the study in 
Spain showing that people between 31 and 64 years old go to the grocery more often than older individuals (Achón et al., 2017).

According to current status, the unemployment rate can also affect shopping frequencies because the literature data are indicating that unemployed family members purchase food and visit grocery stores more frequently (Bawa and Ghosh, 1999). Consumers could be also grouped, according to the time they spend in the shop during one food purchase, into 'quick' and 'regular' shoppers (Kahn and Schmittlein, 1989). Long lasting and not long-lasting food are purchased differently among different age groups because adults buy more often long-lasting food, while adolescents buy more often not long-lasting food (Vemula et al., 2014). The distances from the home to grocery stories certainly influence shopping frequencies. Closer grocery stores can lead to the more frequent purchase of fresh fruits and vegetables (Achón et al., 2017).

Students and retired respondents showed a similar distribution in terms of the food purchase frequency. Respondents of both groups buy food three times per week: employees (private sphere, state sphere) and self-employed people (SEP) reported the same behaviour. Comparing the results is possible to see that state sphere employees (with $8 \mathrm{~h}$ working day) more often do food purchase one time per week; their free time is probably more limited. The unemployed are the most varied group of respondents due to the length of unemployment, age, education, financial resources at their disposal, personal and family conditions, character traits, habits and behaviour. This group of respondents purchases food, mainly daily ( $40 \%$ of respondents), $33 \%$ of them do it 1 time per week and lesser number of them $(27 \%)$ do food purchase 3 times per week.

\section{Food labelling}

Currently, in the European Union, food placed on the market is labelled with mandatory information, which can be extended or supplemented with recommended voluntary data, in accordance with the Regulation (EC) No. 1169/2011. The aim of the Regulation is to enable consumers to make an informed choice of foodstuff, in particular with regard to its origin, health, quality, composition and safeness. From the point of view of consumers' health, hazardous nutritional data include the energy value together with the amount of fat, saturated fatty acids, sugars and salt. UBD and BBD are labels that help and indicate consumers for how long they can without fear of foodborne illness store and consume certain food products. Long-lasting foods can be present on the market even after expiration of BBD because they are produced by technologies effective against foodborne infectious agents or intoxications. However, the quality of these products after expiration of BBD can be affected in the way that consistency, colour, taste and smell are changed. These changes are in relation to chemical composition, water content, $\mathrm{pH}$ and other parameters of food commodities. Especially, animal foods with a higher fat content containing a higher proportion of unsaturated fatty acids that can readily undergo hydrolytic and oxidative spoilage may exhibit poor quality and recognisable sensory changes in taste and smell. However, not all consumers are aware of this, and therefore, in particular, renaming the date of minimum durability to the date of the highest quality (DHQ) would be beneficial in the way that not only consumers, but also food producers would be aware about quality changes of food commodities.

This kind of food labelling (DHQ) was estimated to be very useful for consumers and marked as a helpful way to improve consumers' healthy food choices. These facts are supported by the survey finding that $2 / 3$ of people read the nutrition labelling before food purchase (Cecchini and Warin, 2016).

Considering the education level, higher education is associated with increase comprehension of food labelling (Gregori et al., 2014; Hawkes and WHO, 2004).

Respondents' preferences towards the change of BBD to the new labelling 'the date of the highest quality' (DHQ) are shown in Figure 3.

The question considering health hazardous side of changing BBD to DHQ was aimed to determine respondents' anxiousness towards foodborne illness in case of labelling change. The last question was intended to monitor the importance of the proposed change (from BBD to DHQ) in terms of respondents' confidence in the application of legislative requirements in practice. The answers were very variable among the six groups of respondents, as shown in Figure 3. To simplify the interpretation of the results in Figure 3, respondents' answers for each question were evaluated comprehensively (the average value of answers was calculated for each group). It can be unambiguously stated that the desired positive responses exceeded 50\%, while the amount of negative responses was less than half of this value (about 22\%). The results of the unemployed respondents indicated their highest support (approximately 33\%) for renaming BBD (according to them this changing would result in better understanding of labelling), while $5 \%$ of them would worry about their own health if BBD is changed. These findings can be probably explained by a large variety of personal life situation among these respondents, especially in the case of socially weak long-term unemployed homeless people 


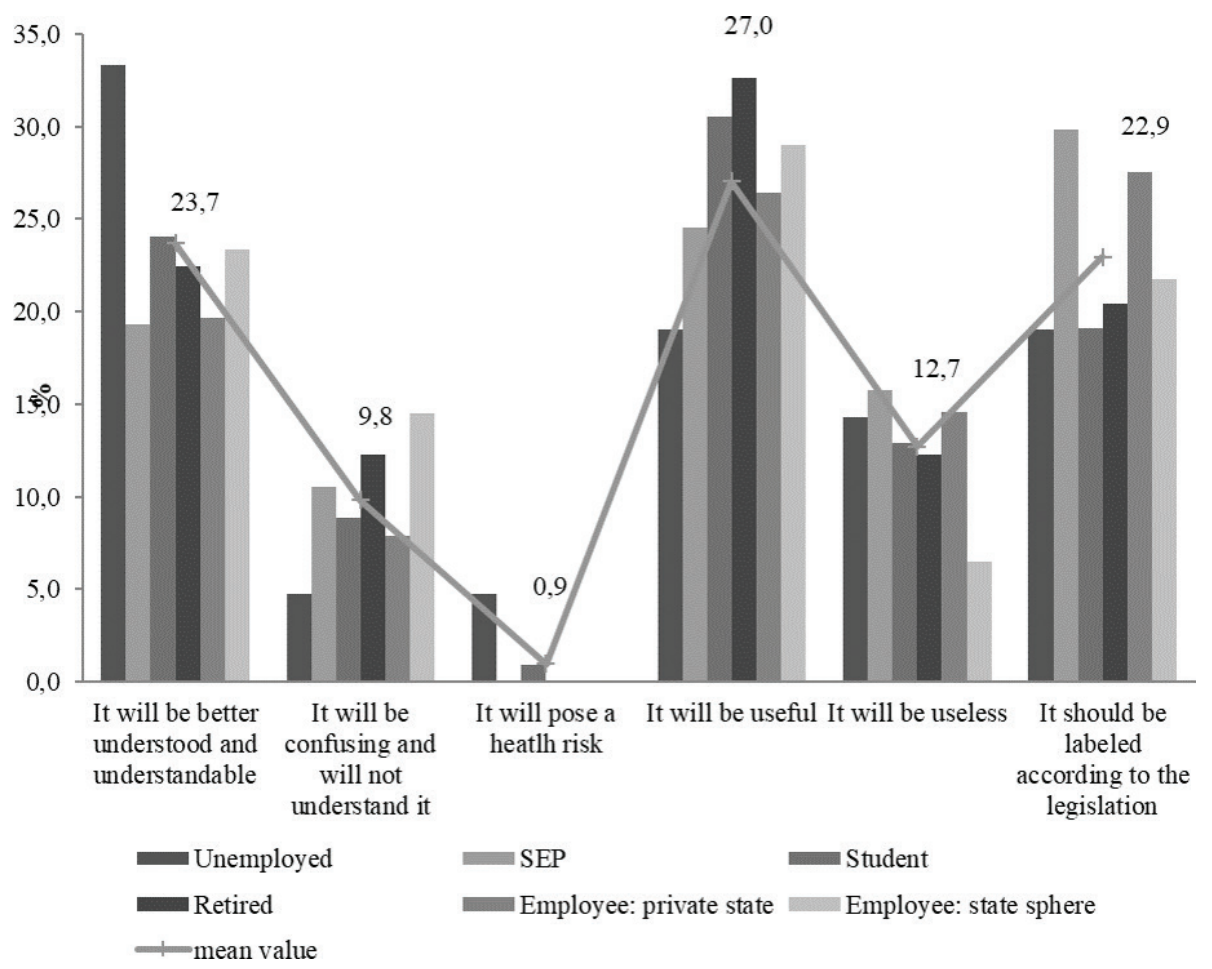

Figure 3. Respondents' reaction to the changes of best before date to date of the highest quality according to their current status.

whose health is usually weakened by various diseases, malnutrition and addictions (alcohol, drugs) because some health problems may be directly related to alimentary infection. Respondents of the other groups (except about $1 \%$ of students) do not see any problem in renaming $\mathrm{BBD}$ and they did not express worries about their own health. The implementation of the term DHQ in legislation is clearly very important for sole traders (approximately 29\%) and also respondents employed in the private sector (approximately $27 \%$ ), who are likely to be more actively working with legislation in their work and therefore better be aware of their importance for practice (sanctions in case of non-application). The statements of the other groups on this issue, including the unemployed respondents, were practically the same.

Monthly income, number of persons in the family and gender did not affect significantly $(P<0.05)$ respondents' answers towards the change of BBD. The date of food expiration is the main object for consumers' observations on food labelling (represented as BBD and UBD). Studies are indicating that women more often checked labelling and retired persons do not check labelling so often. Nutritional information on food labelling was found to be important only for $16 \%$ of respondents, though female respondents cared more about this part of food labelling. In European studies (carried out in the Bosnia and Herzegovina and Macedonia), respondents (62\%) stressed out that BBD or UBD is the most important part of food labelling, same as that bigger letters on food labelling would be more useful (Alibabić et al., 2012; Nakov et al., 2017). In the study carried out in India, it was observed that consumers do not check food labelling so often and the most important for them on food labelling is brand name, then BBD and less important for them is the nutritional information on food labelling. The differences between European and Asian countries are observable. However, in the same study it was revealed that the education level of respondents played an important role in respondents' dedication to read nutrition information on food labelling (Vemula et al., 2014).

Respondents (10-25\%) stated that they consume food after the expiration of BBD, but not negligible number of respondents replied that they consume food at least sometimes after the expiration of BBD (sometimes BBD: approximately $40-60 \%$ ). According to chi-square test in our study, the SEP consume food after the BBD expiration statistically significant $(P<0.05)$ more often in comparison to other groups; retired respondents consume food after BBD expiration statistically significant $(P<0.05)$ the least often (Figure 4) . The retired respondents (about $39 \%$ ) usually do not consume food after BBD expiration and paradoxically the unemployed respondents (about $32 \%$ ) also do not consume food after BBD expiration. For both groups (unemployed, retired), this attitude can be 


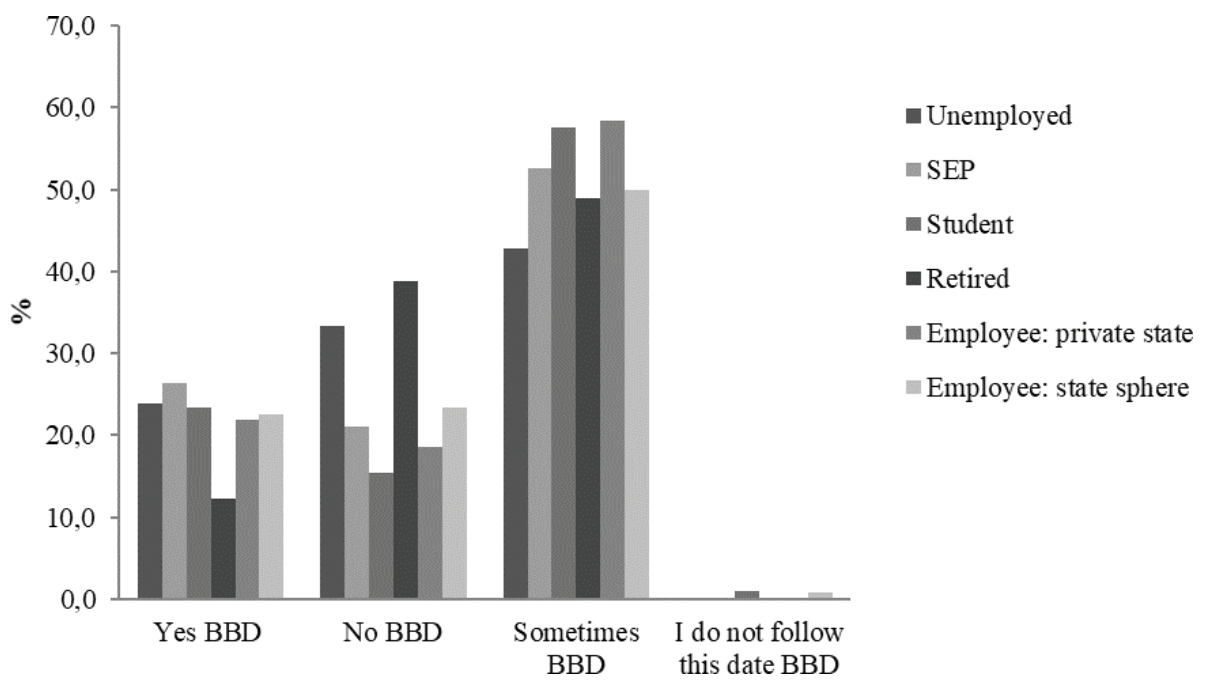

Figure 4. Consumption of food after best before date expiration.

justified by purchasing a limited quantity of food, shortly after purchase. Only the minimum percentages of respondents (student, employee: state sphere) pay attention to BBD information.

Our study also indicated that the frequency of checking BBD is not in dependence $(P>0.05)$ with respondents' salaries, gender and households' numbers. Another study, carried out in Spain, found that women check BBD more often due to their more frequent food purchase (Achón et al., 2017). On the contrary, controlling UBD is not statistically significant $(P>0.05)$ with respondents' current status, salary, gender and household numbers.

The frequency of shopping and the size of grocery stores that are visited by respondents did not influence (measured by one-way ANOVA $P>0.05$ ) respondents' preferences towards opinion about the new labelling of BBD. However, respondents who less frequently purchase food in big grocery shops (Globus, Kaufland, MAKRO Cash \& Carry ČR and Tesco) support more the offered changes of BBD.

The results of the survey indicate that consumers' preferences to consume food after BBD and UBD expiration do not have influence $(P<0.05)$ on respondents' preferences towards opinion about the new labelling of BBD.

\section{Food waste versus food labelling}

Food behaviour, food products, package and labelling are interrelated with food waste (WRAP, 2017). The consumers' behaviour is a factor to understanding the causes and consequences of food waste reduction (Wilson et al., 2017).
The prolongation of time to consume the food products is in relation to shelf life. Date labelling reduces significantly food waste in households, such as use BBD instead of UBD. The shelf life of food products can be increased significantly by optimal storage, but it is limited by consumers' preferences to read food labelling. This statement is supporting the fact that food labelling plays an important part also in food waste issues (WRAP, 2017), as found in our survey and gained respondents' preferences (Figure 6).

A recent study carried out from the European Commission in 2018 estimates 'up to $10 \%$ of 88 million tonnes of food waste generated annually in the EU are linked with date marking' (Anthesis et al., 2018). Currently, there is a debate at the European Commission to rename the BBD to reduce unnecessary food waste (Thompson et al., 2018; Wilson et al., 2017).

\section{Consumers' preferences about healthy food}

At the present time, very often healthier food immediately means that this food has a higher price. According to our survey, the majority of respondents considered it unnecessary for healthier food to be always more expensive (39.8\%; $\mathrm{n}=433)$ and $57.6 \%(\mathrm{n}=627)$ thought that higher price is reasonable only if that kind of food is more expensive to be produced. About $84.6 \%(n=918)$ of respondents also thought that healthy food price should be supported by state subsidy because higher price can affect (stated by $90.4 \%$ of respondents: $n=984$ ) the amount of this food included in citizens' daily diet and consequently affect their health.

The US Department of Agriculture (USDA) identified three Healthy Food Patterns: Healthy Vegetarian Pattern, Healthy US-Style Pattern and Healthy 


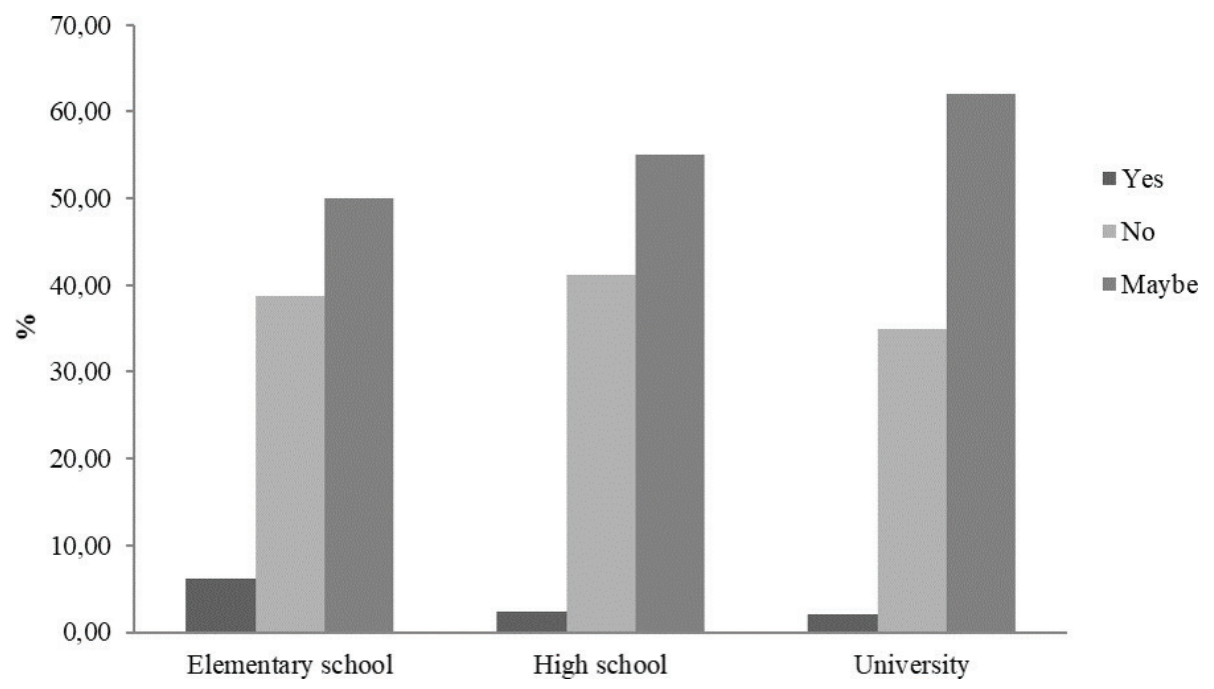

Figure 5. Healthier foods should be more expensive based on completed education.

Mediterranean-Style Pattern. All three Healthy food Patterns when compared with existing National Health and Nutrition Examination Survey (NHANES, 2019) diets include more vegetables, legumes, fruit, whole grains, low fat dairy, lean meats and seafood.

As shown in Figure 5, among respondents of all groups, irrespective of their level of education, there is a dominant perception (about $50-63 \%$ of respondents) that healthier foods should probably be more expensive. On the contrary, a relatively high percentage (35-40\%) of respondents believes that healthier foods should be cost-comparable to conventional foods.

Based on education level, less educated people significantly $(P<0.05)$ more supported the thesis that healthy food should be more expensive in comparison with higher educated respondents. According to Hassan and Dimassi (2017) highly educated people have more food labelling knowledge than less educated. Studies are also indicating that students in their first university year mostly consume unhealthy food (Deliens et al., 2014). According to Kostakis (2014), consumers with higher education choose more preferably healthier food.

As expected, respondents from the retired group unequivocally (approximately 70\%) reject a higher price for healthier foods. The unemployed respondents had a similar, though not so clear, perception about the price of healthier food; only a minority (about 5\%) agreed that healthier food should cost more (Figure 6).

All three income groups responded similarly, as shown in Figure 7, though certain differences can be observed. The group with the highest financial income very cautiously (about 5\% of respondents) agreed with higher prices for healthier food. On the contrary, respondents with lower income statistically significantly $(P<0.05)$ more expressed that healthier food should be more expensive (Figure 7).

These findings can be in relation with education level because people with higher education receive higher salaries. Higher salaries and education level increase additional purchases of food, though it does not mean that nutritional profile of daily diet would be increased too (Appelhans et al., 2012; Kostakis, 2014). According to Jetter and Casady (2006), the price of healthier food in California is higher and represents the purchase barrier. Healthier foods are also less available in low-income neighbourhoods (Lennernäs et al., 1997). High-energy-dense diets, composed of fats, added sugar or refined grains, are in relationship with low prices and it could explain the connection between A non-communicable disease (NCDs) and lower SES (Andrieu et al., 2006; Darmon and Drewnowski, 2015).

Individuals having lower SES consume less fruit and vegetables (Lennernäs et al., 1997; Pechey et al., 2015); therefore, they have less access and higher exposure to unhealthy foods, principally men consume more unhealthy food (Pechey et al., 2015). The majority of studies concluded that healthier foods are more expensive than unhealthy food (Andrieu et al., 2006; Darmon and Drewnowski, 2015; Jetter and Cassady, 2006; Rao et al., 2013).

In terms of gender, women have more clear-cut views than men on the question of healthier food prices, although both sexes basically responded similarly (Figure 8). However, women supported more (about $60 \%$ ) a higher price for healthier food and accepted more 


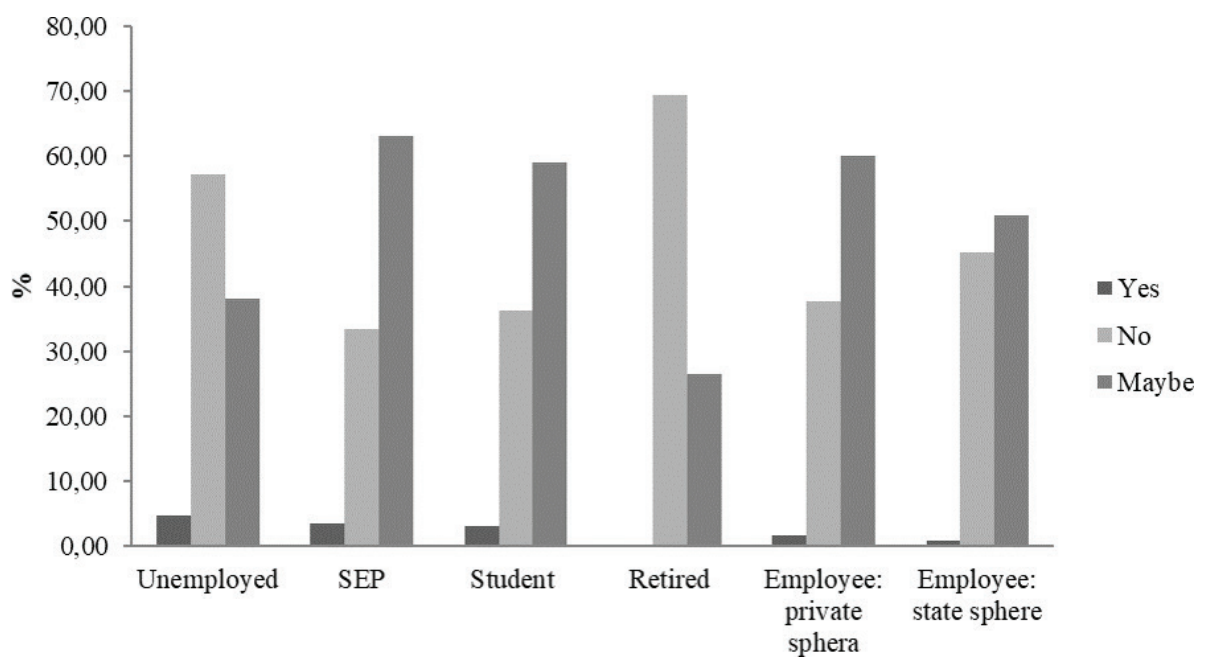

Figure 6. Respondents' reply (according to their current status) on the question: should healthier food be more expensive?

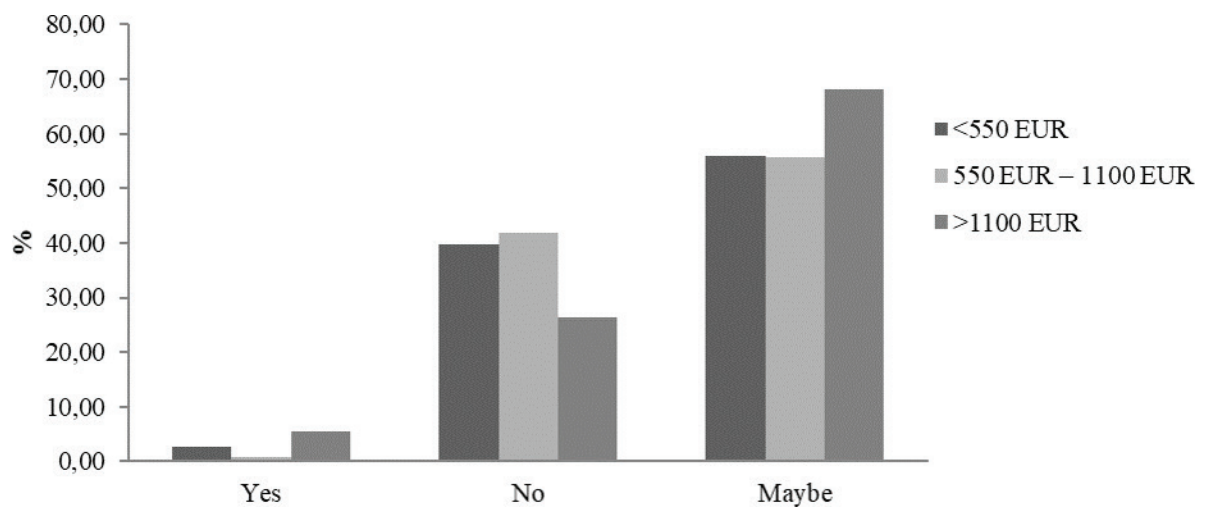

Figure 7. Respondents' reply (according to their monthly) on the question: should healthier food be more expensive?

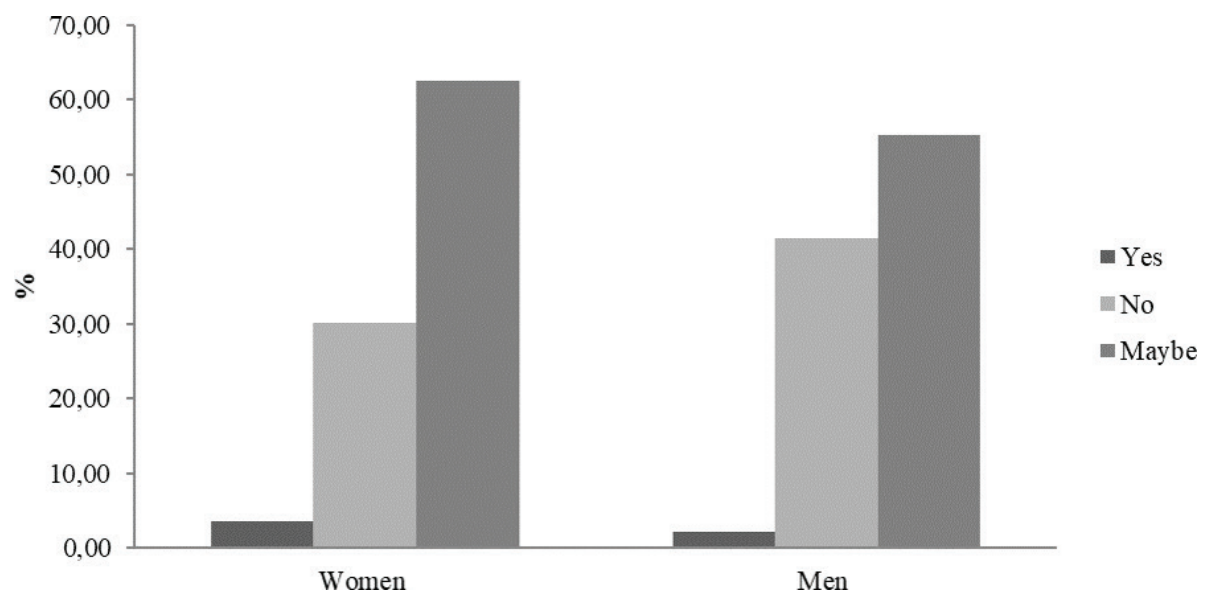

Figure 8. Respondents' reply (according to their gender) on the question: should healthier food be more expensive? 


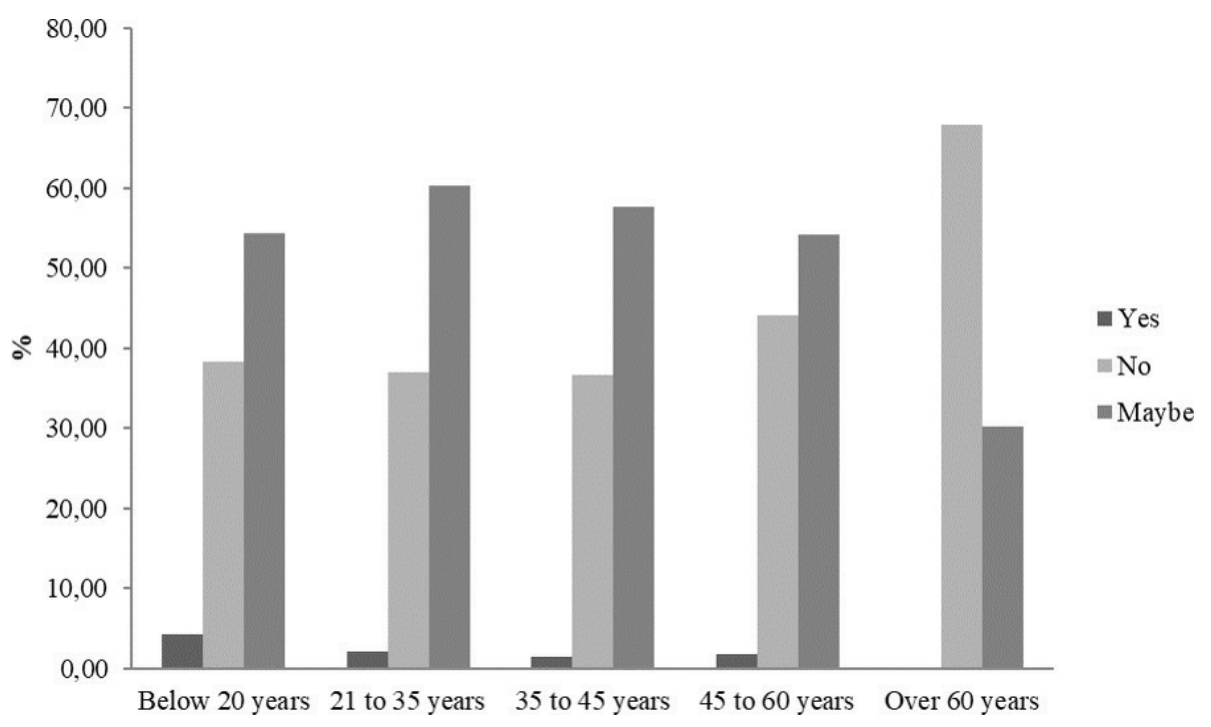

Figure 9. Respondents' reply (according to their age) on the question: should healthier food be more expensive?

readily higher price (about 3\%) than men. A fewer number of women (about 30\%) than men agreed that the price of healthier foods should be comparable to other foods of the same type.

The youngest group of respondents (below 20 years) considered $(P<0.05)$ reasonable higher prices for healthier food (Figure 9) in comparison with older age groups of respondents. On the contrary, the lower price of healthier food is clearly a priority (approximately $70 \%$ ) for the oldest group of respondents, which, of course, is related to usually very limited financial resources available to them. Approximately $30 \%$ of the oldest respondents expressed willing to accept higher prices for healthier foods. Respondents aged 21-60 years had almost the same opinion on the price of healthier foods. This finding is probably in relation with lower income, younger age and lower education level. The recent studies showed that women consume more healthy food (though it can vary a lot in dependence on education level) and men consume less fruit and vegetables (Caine-Bish and Scheule, 2009; Cooke and Wardle, 2005; Grunert et al., 2010; Pechey et al., 2015; Roos et al., 1998).

There are different actions worldwide and in the European Union with which have been tried to improve the daily diet of citizens, such as food-based dietary guidelines (FBDGs) (Montagnese et al., 2015). The guide is focusing on incorporation of accessible and available food in each country (WHO, 2003). The food preferences and the food choices are not only affected by age, gender, food taste, but also remarkably by food price. Hence, the price is lower when calculated per calorie in high-density food, more accessible and more palatable food (Beydoun et al., 2008; Drewnowski and Darmon, 2005; Harrison et al., 2010). The important factor is certainly food labelling that directs consumers to choose healthier products (Cecchini and Warin, 2016). Finally, eating healthy food with diversity is in relation with healthy life expectancy being prevention for diseases, that is to say, to prevent NCDs (Miyamoto et al., 2019).

\section{Conclusion}

The research found high acceptance among all socio-demographic groups for the new labelling of the BBD that would, according to consumers, be more suitable to be the DHQ. This new type of labelling would probably in certain percentage lead to the reduction of food waste. The part of the survey also indicated a relationship between considerations towards the price of healthy food and respondents' education level; the finding that highly educated individuals the finding that highly educated individuals do not consider that healthy food should be more expensive only due to the preferences suggesting that those kind of food can be beneficial for health when included in the daily diet.

\section{Conflicts of interest}

The authors declare no conflict of interest or relationship, financial or otherwise.

\section{Compliance with ethical standards}

This study does not involve any human testing. 


\section{Funding}

The research was part of the institutional funding.

\section{References}

Achón, M., Serrano, M., García-González, Á., Alonso-Aperte, E. and Varela-Moreiras, G., 2017. Present food shopping habits in the Spanish adult population: a cross-sectional study. Nutrients 9(5): 508. https://doi.org/10.3390/nu9050508

Alibabić, V., Mujić, I., Rudić, D., Bajramović, M., Jokić, S., Šertović, E. and Ruțić, A., 2012. Labeling of food products on the B\&H market and consumer behavior towards nutrition and health information of the product. Procedia-Social and Behavioral Sciences 46: 973-979. https://doi.org/10.1016/j.sbspro.2012.05.233

Andrieu, E., Darmon, N. and Drewnowski, A. 2006. Low-cost diets: more energy, fewer nutrients. European Journal of Clinical Nutrition 60(3): 434. https://doi.org/10.1038/sj.ejcn.1602331

Anthesis, ICF and WRAP, 2018. Market study on date marking and other information provided on food labels and food waste prevention. Directorate-General for Health and Food safety (European Commission), Final Report. WRAP, Brussels. ISBN 978-92-79-73421-2

Appelhans, B.M., Milliron, B.J., Woolf, K., Johnson, T.J., Pagoto, S.L., Schneider, K.L. and Ventrelle, J.C., 2012. Socioeconomic status, energy cost, and nutrient content of supermarket food purchases. American Journal of Preventive Medicine 42(4): 398-402. https:// doi.org/10.1016/j.amepre.2011.12.007

Bawa, K. and Ghosh, A., 1999. A model of household grocery shopping behavior. Marketing Letters 10(2): 149-160. https://doi. org/10.1023/A:1008093014534

Beydoun, M.A. and Wang, Y., 2008. Do nutrition knowledge and beliefs modify the association of socio-economic factors and diet quality among US adults? Preventive Medicine 46(2): 145-153. https://doi.org/10.1016/j.ypmed.2007.06.016

Beydoun, M.A., Powell, L.M. and Wang, Y., 2008. The association of fast food, fruit and vegetable prices with dietary intakes among US adults: is there modification by family income? Social Science \& Medicine 66(11): 2218-2229. https://doi.org/10.1016/j. socscimed.2008.01.018

Caine-Bish, N.L. and Scheule, B., 2009. Gender differences in food preferences of school-aged children and adolescents. Journal of School Health 79(11): 532-540. https://doi. org/10.1111/j.1746-1561.2009.0044.x.x

Cecchini, M. and Warin, L., 2016. Impact of food labelling systems on food choices and eating behaviours: a systematic review and meta-analysis of randomized studies. Obesity Reviews 17(3): 201-210. https://doi.org/10.1111/obr.12364.

Cooke, L.J. and Wardle, J., 2005. Age and gender differences in children's food preferences. British Journal of Nutrition 93(5): 741746. https://doi.org/10.1079/BJN20051389

Darin-Mattsson, A., Fors, S. and Kåreholt, I., 2017. Different indicators of socioeconomic status and their relative importance as determinants of health in old age. International Journal for Equity in Health 16(1): 173. https://doi.org/10.1186/s12939-017-0670-3
Darmon, N. and Drewnowski, A., 2015. Contribution of food prices and diet cost to socioeconomic disparities in diet quality and health: a systematic review and analysis. Nutrition Reviews 73(10): 643-660. https://doi.org/10.1093/nutrit/nuv027

Deliens, T., Clarys, P., De Bourdeaudhuij, I. and Deforche, B., 2014. Determinants of eating behaviour in university students: a qualitative study using focus group discussions. BMC Public Health 14(1): 53. https://doi.org/10.1186/1471-2458-14-53

Drewnowski, A. and Darmon, N., 2005. Food choices and diet costs: an economic analysis. The Journal of Nutrition 135(4): 900-904. https://doi.org/10.1093/jn/135.4.900

Food Standards Agency (FSA), 2018. Best before and use-by date. Available at: https://www.food.gov.uk/safety-hygiene/ best-before-and-use-by-dates.

Gregori, D., Ballali, S., Vögele, C., Gafare, C.E., Stefanini, G. and Widhalm, K., 2014. Evaluating food front-of-pack labelling: a pan-European survey on consumers' attitudes toward food labelling. International Journal of Food Sciences and Nutrition 65(2): 177-186. https://doi.org/10.3109/096374866.2013.854743

Grunert, K.G., Wills, J.M. and Fernández-Celemín, L., 2010. Nutrition knowledge, and use and understanding of nutrition information on food labels among consumers in the UK. Appetite 55(2): 177-189. https://doi.org/10.1016/j. appet.2010.05.045

Harrison, M., Lee, A., Findlay, M., Nicholls, R., Leonard, D. and Martin, C., 2010. The increasing cost of healthy food. Australian and New Zealand Journal of Public Health 34(2): 179-186. https:// doi.org/10.1111/j.1753-6405.2010.00504.x

Hassan, H.F. and Dimassi, H., 2017. Usage and understanding of food labels among Lebanese shoppers. International Journal of Consumer Studies 41(5): 570-575. https://doi.org/10.1111/ ijcs. 12368

Hawkes, C. and WHO. Noncommunicable Diseases \& Mental Health Cluster, 2004. Nutrition labels and health claims: the global regulatory environment/Corinna Hawkes. Geneva: World Health Organization. Available at: https://apps.who.int/iris/ handle/10665/42964.

Jetter, K.M. and Cassady, D.L. 2006. The availability and cost of healthier food alternatives. American Journal of Preventive Medicine 30(1): 38-44. https://doi.org/10.1016/j. amepre.2005.08.039

Kahn, B.E. and Schmittlein, D.C., 1989. Shopping trip behavior: an empirical investigation. Marketing Letters 1(1): 55-69. https:// doi.org/10.1007/BF0043614.9

Kostakis, I., 2014. The determinants of households' food consumption in Greece. International Journal of Food and Agricultural Economics (IJFAEC) 2(2): 17.

Lennernäs, M., Fjellström, C., Becker, W., Giachetti, I., Schmitt, A., De Winter, A.M. and Kearney, M., 1997. Influences on food choice perceived to be important by nationally-representative samples of adults in the European Union. European Journal of Clinical Nutrition 51: 36-40

Milne, R., 2012. Arbiters of waste: date labels, the consumer and knowing good, safe food. The Sociological Review 60: 84-101. https://doi.org/10.1111/1467-954X.12039 
Miyamoto, K., Kawase, F., Imai, T., Sezaki, A. and Shimokata, H., 2019. Dietary diversity and healthy life expectancy-an international comparative study. European Journal of Clinical Nutrition 73(3): 395. https://doi.org/10.1038/s41430-018-0270-3

Montagnese, C., Santarpia, L., Buonifacio, M., Nardelli, A., Caldara, A.R., Silvestri, E. and Pasanisi, F., 2015. European food-based dietary guidelines: a comparison and update. Nutrition 31(7-8): 908-915. https://doi.org/10.1016/j.nut.2015.01.002

Nakov, G., Ivanova, N., Damyanova, S., Stamatovska, V. and Necinova, L., 2017. Public opinion surveys of consumers for manner of labeling the food product in the Republic of Macedonia. Ukrainian Food Journal 6(1): 154-164. https://doi. org/10.24263/2304-974X-2017-6-1-17

Namin, A. and Dehdashti, Y., 2019. A "hidden" side of consumer grocery shopping choice. Journal of Retailing and Consumer Services 48: 16-27. https://doi.org/10.1016/j.jretconser.2019.01.009

National Health \& Nutrition Examination Survey, NHANES, 2019. CDC/National Center for Health Statistics. Available at: https:// www.cdc.gov/nchs/nhanes/index.htm.

Pechey, R., Monsivais, P., Ng, Y.L. and Marteau, T.M., 2015. Why don't poor men eat fruit? Socioeconomic differences in motivations for fruit consumption. Appetite 84: 271-279. https://doi. org/10.1016/j.appet.2014.10.022

Rao, M., Afshin, A., Singh, G. and Mozaffarian, D., 2013. Do healthier foods and diet patterns cost more than less healthy options? A systematic review and meta-analysis. British Medical Journal 3(12): e004277. https://doi.org/10.1136/bmjopen-2013-004277

Regulation (EU) No 1169/ 2011 of the European Parliament and of the Council of 25 October 2011 on the provision of food information to consumers, amending Regulations (EC) No 1924/2006 and (EC) No 1925/2006 of the European Parliament and of the Council, and repealing Commission Directive 87/250/EEC, Council Directive 90/496/EEC, Commission Directive 1999/10/ EC, Directive 2000/13/EC of the European Parliament and of the Council, Commision Directives 2002/67/EC and 2008/5/EC and Commission Regulation (EC) No 608/2004 (Text with EEA relevance).

Roos, E., Lahelma, E., Virtanen, M., Prättälä, R. and Pietinen, P., 1998. Gender, socioeconomic status and family status as determinants of food behaviour. Social Science \& Medicine 46(12):1519-1529. https://doi.org/10.1016/S0277-9536(98)00032-X

The Waste and Resources Action Programme (WRAP), 2017. Helping consumers reduce food waste, Retail Survey 2015. Final Report. WRAP, Brussels.

Thompson, B., Toma, L., Barnes, A.P. and Revoredo-Giha, C., 2018. The effect of date labels on willingness to consume dairy products: implications for food waste reduction. Waste Management 78: 124-134. https://doi.org/10.1016/j.wasman.2018.05.021

Van Boxstael, S., Devlieghere, F., Berkvens, D., Vermeulen, A. and Uyttendaele, M., 2014. Understanding and attitude regarding the shelf life labels and dates on pre-packed food products by Belgian consumers. Food Control 37: 85-92. https://doi.org/10.1016/j. foodcont.2013.08.043

Vemula, S.R., Gavaravarapu, S.M., Mendu, V.V.R., Mathur, P. and Avula, L., 2014. Use of food label information by urban consumers in India-a study among supermarket shoppers. Public Health Nutrition 17(9): 2104-2114. https://doi.org/10.1017/ S1368980013002231

WHO, 2003. Food based dietary guidelines in the WHO European region. Available at: http://www.euro.who.int/en/health-topics/ diseaseprevention/nutrition/publications/technical-documents/ dietary-recommendations-and-nutritional-requirements/foodbased-dietary-guidelines-in-the-who-european-region (last accessed 26 March 2019)

Wilson, N.L., Rickard, B.J., Saputo, R. and Ho, S.T., 2017. Food waste: the role of date labels, package size, and product category. Food Quality and Preference 55: 35-44. https://doi.org/10.1016/j. foodqual.2016.08.004 